\title{
The Increase of Fracture Toughness with Solution Annealing Temperature in 18Ni Maraging 300 Steel
}

\author{
Venceslau Xavier de Lima Filho ${ }^{a *}$ (D), Tiago Nunes Lima ${ }^{b}$, Sandro Griza ${ }^{b}$,

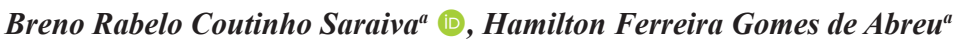 \\ ${ }^{a}$ Universidade Federal do Ceará, Programa de Pós-Graduação em Engenharia e Ciências de Materiais, \\ Fortaleza, CE, Brasil \\ ${ }^{b}$ Universidade Federal de Sergipe, Programa de Pós-Graduação em Ciência e Engenharia de \\ Materiais, Cristóvão, SE, Brasil
}

Received: October 12, 2020; Revised: February 21, 2021; Accepted: March 24, 2021

\begin{abstract}
Maraging steels are a class of ultra high strength steels of special importance due to their extremely high mechanical strength and good toughness. In this work, the effects of the solution annealing temperature on the mechanical properties of the maraging 300 steels were evaluated, in order to maximize the toughness without considerable detriment of the mechanical strength. Five solution annealing temperatures were evaluated. The characterization of the mechanical properties was done by tests of Rockwell $\mathrm{C}$ hardness, Charpy-V impact toughness, and tensile and fracture toughness in plane strain. The results obtained show that the fracture toughness increases, and the tensile strength decreases with the temperature of the solution annealing. In this way it was possible to find a heat treatment condition in which it was possible to raise about $20 \%$ of the toughness with a loss of only $6 \%$ in the tensile strength.
\end{abstract}

Keywords: Maraging 300; solution annealing; microstructure; fracture toughness.

\section{Introduction}

There are some high technology applications, such as aircraft, rockets, and also a high-speed rotator as an ultracentrifuge for the enrichment of uranium that require optimized alloys, keeping high mechanical strength and fracture toughness at the same time ${ }^{1,2}$. Maraging steels are a class of ultra-highstrength alloys, essentially Fe-Ni-Mo-Co and low carbon. They exhibit BCC structure, low hardness martensite after solution annealing, and high strength after aging ${ }^{3-6}$. Solution annealing at $820^{\circ} \mathrm{C}$ for $1 \mathrm{~h}$, followed by aging at $480{ }^{\circ} \mathrm{C}$ for $3 \mathrm{~h}$ is the heat treatment generally applied to achieve the higher mechanical strength of the Maraging steels ${ }^{7-9}$.

Forging, rolling, flow-forming, and drawing are some of the fabrication processes used to manufacture components of Maraging. The lack of carbon leads to good weldability and therefore makes these materials preferred candidates for additive manufacturing techniques, such as selective laser melting ${ }^{10}$.

Despite the low carbon content $(<0.03 \mathrm{wt} \%)$, the high nickel ( $18 \mathrm{wt} \% \mathrm{Ni})$ in maraging steels ensures that martensite forms at any cooling speed after solution annealing. The low carbon bec martensitic matrix is hardened during aging. Fine-scale intermetallic compounds, such as the $\mathrm{Ni}_{3}(\mathrm{Ti}$, Mo) precipitates in the matrix. Other phases, like the $\mathrm{Fe}_{2} \mathrm{Mo}$ Laves phase, $\mathrm{S}$ phase, $\omega$ phase, and $\mathrm{Fe}_{7} \mathrm{Mo}_{6} \mu$-phase, were also reported in Maraging steels after a long period of aging ${ }^{11,12}$. The presence of $\mathrm{TiC}$ precipitates, despite the

*e-mail: venceslau@ifce.edu.br. low carbon content, was observed in works published in the literature ${ }^{13,14}$. This presence is probably due to the non-dissolution of these carbides during the solution annealing process ${ }^{15}$.

When increasing the temperature of the solution annealing, the austenite grain size grows slowly up to $950{ }^{\circ} \mathrm{C}$, once the delay of the particle dissolution arrests the transposition of the grain boundaries of the particles ${ }^{16,17}$. However, solution annealing at temperatures higher than $1000{ }^{\circ} \mathrm{C}$ promotes increased mobility of grain boundaries, which leads to austenite grain growth, and may also affect the alloy's toughness adversely ${ }^{18-20}$. Furthermore, block-type martensite evolves to lath-type as the temperature of the solution annealing increases ${ }^{21,22}$. During the aging, dislocations in the lath boundaries will be the preferential orientation and nucleation sites for precipitates $^{23}$. Therefore, the competition between the prior austenite grain size and the martensite morphology may affect the mechanical behaviour of Maraging steels.

This study aims to evaluate the effect of the temperature of the solution annealing of hot rolled samples of Maraging steel on austenite grain size and the martensite morphology, and its consequences for a compromise between fracture toughness and tensile strength. The determination of the critical stress intensity factor (KIC) evaluated the fracture toughness. KIC is a property that is a measure of a material's resistance to brittle fracture when a crack is present ${ }^{24}$. 


\section{Materials and Methods}

A Maraging steel bar manufactured by Vacuum Induction Melting/Vacuum Arc Refining, hot forged, and solution annealed at $860{ }^{\circ} \mathrm{C}$ was sliced and hot-rolled, producing $13 \mathrm{~mm}$ thick strips. Table 1 presents the chemical composition.

The stripes were solution annealed in an oven for one hour in temperatures of $820,860,1000,1050$, and $1100^{\circ} \mathrm{C}$. Samples were cooled in water to avoid carbide formation. The aging process was the same for all solution annealed samples i.e., $480^{\circ} \mathrm{C}$ for $3 \mathrm{~h}$. They were measured with $0.02 \mathrm{~mm}$ resolution pachymeter (Mitutoyo ref. 530-119). The roughness of the samples was measured (Mitutoyo model SJ-210). The curvature radius and notches of the tensile, impact and fracture toughness samples were measured in a Hexagon, Optiv Classic 3020 vm. The tests were performed at ambient temperature. The samples were tested in triplicate. At least three images of each sample were used for an image analysis of the austenite grain sizes, martensite morphologies and fractographies. Analysis of variance (One way ANOVA) was performed to determine the statistical differences between results with $\mathrm{p} \leq 0.05$.

Thermodynamic simulation ${ }^{25}$ (ThermoCalc $\AA$, TCF66 database, CALPHAD protocol) allowed calculating the thermodynamic equilibrium for the most stable phases of the system as a function of the chemical composition and the temperature of the solution.

$\mathrm{X}$-ray diffraction analysis (XRD) was performed in a Panalytical X'Pert Pro equipment, with copper radiation and a monochromator. The parameters of the XRD were a voltage of $40 \mathrm{kV}$, a current of $55 \mathrm{~mA}$, a scanning interval from $35^{\circ}$ to $95^{\circ}$ with steps of $0.02^{\circ}$, time per step of $2.5 \mathrm{~s}$ and a scanning speed of $0.008^{\circ} / \mathrm{s}$.

The samples for microstructural analysis were polished with diamond pastes up to $1 / 4 \mu \mathrm{m}$. A first electrolytic etching (20\% chromic acid diluted in distilled water), using $15 \mathrm{~V}$ constant voltage for 45 to $100 \mathrm{~s}$, revealed the austenite grain boundaries. The second etching by immersion in Marble's reagent $(10 \mathrm{~g} \mathrm{CuSO} 4+50 \mathrm{ml} \mathrm{HCl}+50 \mathrm{ml}$ distilled water $)$ for 5 to $15 \mathrm{~s}$, allowed characterizing the martensite ${ }^{19}$. An optical microscope (Olympus, GX51) and image analyser (Analysis Get $\mathrm{It}\left({ }^{\mathrm{S}}\right)$ allowed measuring the austenite grain size by measuring the diameter of equivalent area with individual grains, according to the intercept method, in accordance to the ASTM E112-13 standard, as well as the analysis of the martensite morphology. Scanning electron microscopy (SEM) (FEI XL30) operating at $20 \mathrm{kV}$ in secondary electron mode allowed the microstructural characterization and the fractographic analysis. The samples were polished and concomitantly etched $\left(0.1 \mathrm{~g}\right.$ of $\left(\mathrm{NH}_{4}\right)_{2} \mathrm{~S}_{2} \mathrm{O}_{8}+10 \mathrm{ml}$ colloidal silica) in a micro-polisher (Buehler, Minimet 1000) for 3 to $4 \mathrm{~h}$ to make possible an electron back scatter diffraction analysis (EBSD) (Oxford Instruments HKL CHANNEL $5 \circledR)$. The EBSD images were analysed with the Tango ${ }$ image analyser, both to characterize and to measure the blocks and lath martensite.

Sub-size specimens $(5 \times 10 \times 55 \mathrm{~mm}$, roughness $\mathrm{Ra}=1.9 \mu \mathrm{m}$ ) for $\mathrm{V}$-notched Charpy impact tests were prepared
(Charpy tester WPM 400/69/49, $150 \pm 0.5 \mathrm{~J}$ ), according to the ASTM E23-16b standard. The V-notch was manufactured by broaching (Time L71-UV) on the face with a width of $5 \mathrm{~mm}$, following the plate's rolling direction. Rockwell $\mathrm{C}$ hardness tests (M/Sussen Wolpert Testor HT1-super) were repeated 8 times for each sample. Cylindrical sub-size samples $(6 \mathrm{~mm}$ diameter and $30 \mathrm{~mm}$ gauge length) allowed tensile tests (TIME, WDW 300E), which were conducted at $0.5 \mathrm{~mm} / \mathrm{min}$ loading velocity, according to the ASTM E8/E8M-16a standard. All samples were polished up to $1200 \mathrm{Mesh}$ prior to tensile testing. The fracture toughness tests to determine the critical stress intensity factor (KIC) were carried out according to the BS 7448-2 and ISO 12135-16 standards. Samples of type SENB (11 x 11 x $51 \mathrm{~mm}$, roughness Ra of $0.8 \mu \mathrm{m}$ ) notch were machined at the plate's rolling direction by wire electroplating. Pre-cracks of $2.0 \mathrm{~mm}$ were produced by fatigue (MTS Landmark370.10). The determinations of $\mathrm{KIC}$ were performed at $\mathrm{K}=1.7 \mathrm{MPa} \cdot \mathrm{m}^{0.5} \cdot \mathrm{s}^{-1}$. Fracture surface measurements were performed using a stereomicroscope (Zeiss Stemi 2000C) and image analyzer (Image J®), to verify the pre-crack length and the other requirements given by the standards applied in this test. The data were analyzed with the one-way-ANOVA test (Statistica ${ }^{\circledR}$ - Informer Technologies, Inc.) to compare the mean effect of the tensile properties, hardness, Charpy impact energy and fracture toughness. After that, Fisher's F test was used to verify the representativeness and validate the results. The results were presented in the form of arithmetic media and standard deviation (SD). The significance level of the ANOVA test was located when $\mathrm{p} \leq 0.05$.

\section{Results and Discussion}

Phase simulations are useful to predict the phases of a given alloy, with a certain accuracy ${ }^{23}$. Figure 1 shows a zoom of stable phases as a function of temperature on a Thermocalc simulation for Maraging 300. The vertical line is the end of transformation of martensite in austenite.

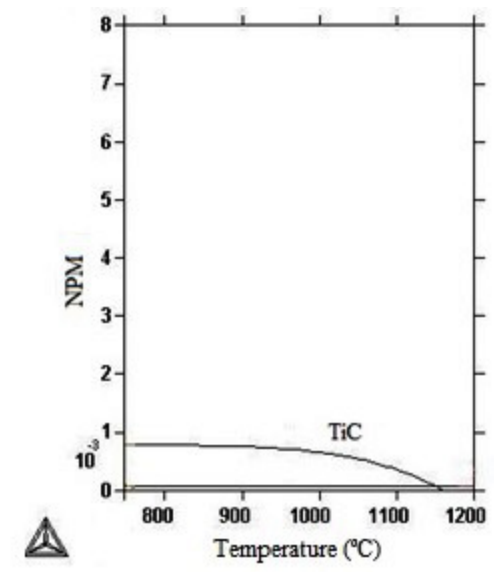

Figure 1. The simulation indicates that undissolved $\mathrm{TiC}$ persist above $1100{ }^{\circ} \mathrm{C}$ in the solution annealed Maraging 300 steel.

Table 1. Chemical composition of the $18 \mathrm{Ni}$ class 300 Maraging steel (wt $\%$ ).

\begin{tabular}{ccccccccccc}
\hline $\mathrm{Ni}$ & $\mathrm{Mo}$ & $\mathrm{Co}$ & $\mathrm{Ti}$ & $\mathrm{Al}$ & $\mathrm{C}$ & $\mathrm{Mn}$ & $\mathrm{Se}$ \\
\hline 18.4 & 5.04 & 9.35 & 0.76 & 0.1 & 0.01 & 0.02 & 0.05 & $\mathrm{Bal}$ & \\
\hline
\end{tabular}


After $670^{\circ} \mathrm{C}$, the only phases present are austenite and TiC. TiC second phase particles are stable at temperatures up to approximately $1150^{\circ} \mathrm{C}$. Carbides occur preferentially in the austenite grain boundaries, anchoring the boundary and hindering grain growth. The XRD analysis detected only martensite (Figure 2). The TiC volumetric fraction

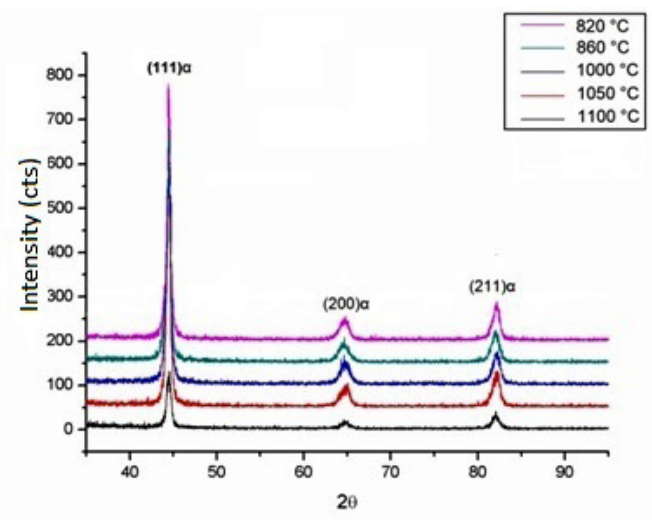

Figure 2. XRD of the Maraging 300 solution annealed at different temperatures. predicted by the phase simulation was 0.001 too low to be detected by XRD analysis. The volumetric fraction predicted for austenite was 0.999 .

The austenite grain grows sharply from $1000^{\circ} \mathrm{C}$ (Figure 3). The austenite grain size ranges from 6.4 to $46.0 \mu \mathrm{m}$ between the temperatures of 820 and $1050^{\circ} \mathrm{C}$, but it jumps to $111.8 \mu \mathrm{m}$ at $1100^{\circ} \mathrm{C}$, in agreement with the historical studies of Rack ${ }^{22}$ and Maxwell et al. ${ }^{26}$. The second phases anchor the austenite boundaries, thus hindering the growth of the austenite grains. It seems that the solution annealing above $1000^{\circ} \mathrm{C}$ some carbides disperse into austenite grains, releasing the boundary mobility.

The martensitic hierarchical microstructure is composed of several plates, which grow together with each austenite grain (Figure 4). The martensite plates are more equi-axial up to $860^{\circ} \mathrm{C}$, when they become martensitic blocks, either of the same orientation or blocks separated by high boundary angles, from solution annealing at $1000{ }^{\circ} \mathrm{C}$ (Figure 5). The increase in temperature promotes the formation of acicular lathes along the martensite blocks. The lath martensite with high density of dislocation tangles has the same habit plane as the martensitic blocks ${ }^{27}$. Lath martensite is evident in the sample solution annealed at $1100{ }^{\circ} \mathrm{C}$ (Figure 6).

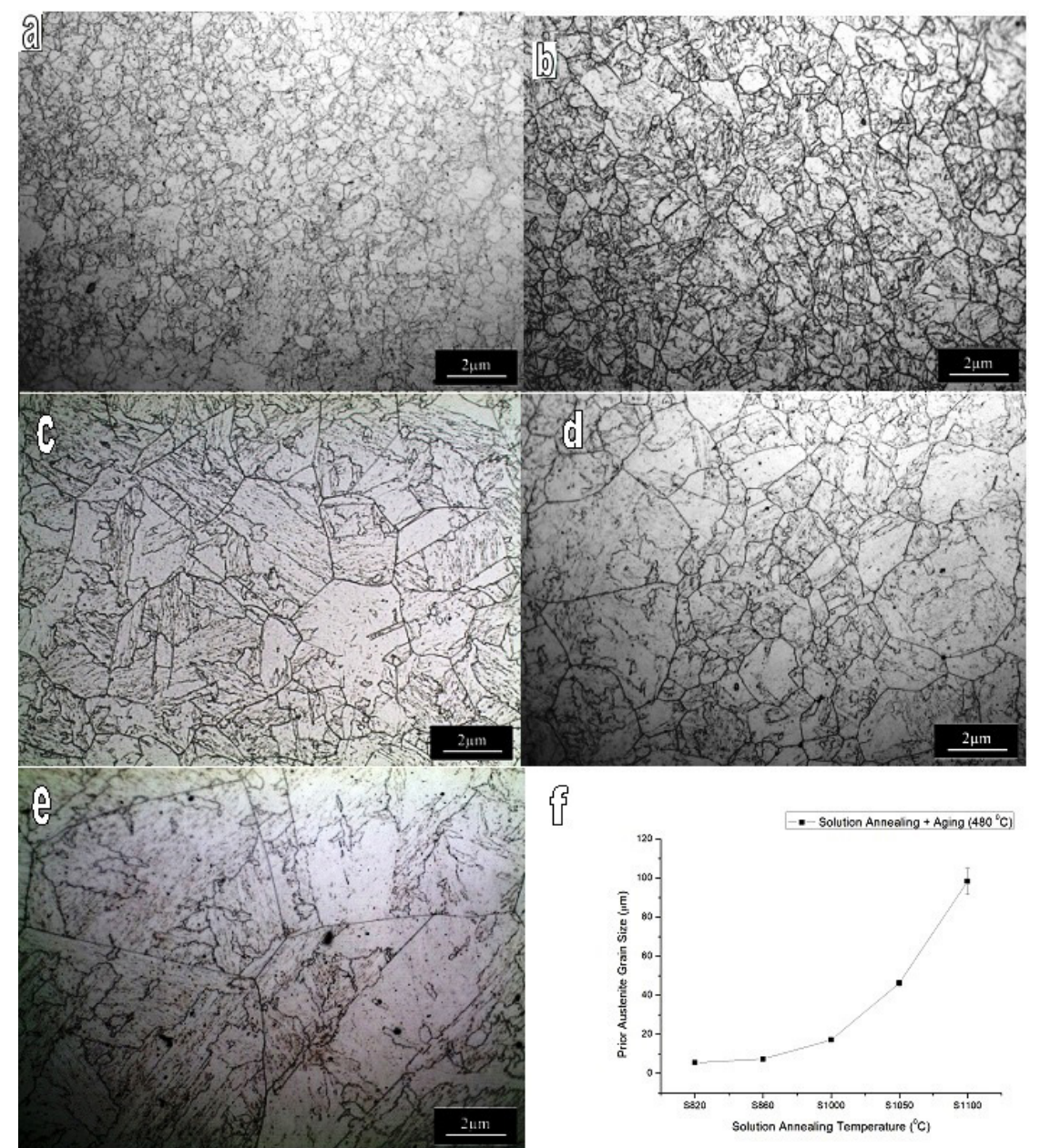

Figure 3. Prior austenite grain size as a function of temperature of solution annealing: $820^{\circ} \mathrm{C}(\mathrm{a}) ; 860^{\circ} \mathrm{C}(\mathrm{b}) ; 1000^{\circ} \mathrm{C}(\mathrm{c}) ; 1050^{\circ} \mathrm{C}(\mathrm{d}) ;$ $1100^{\circ} \mathrm{C}(\mathrm{e})$. The graph (f) correlates the grain size and the temperature of the solution annealing. 


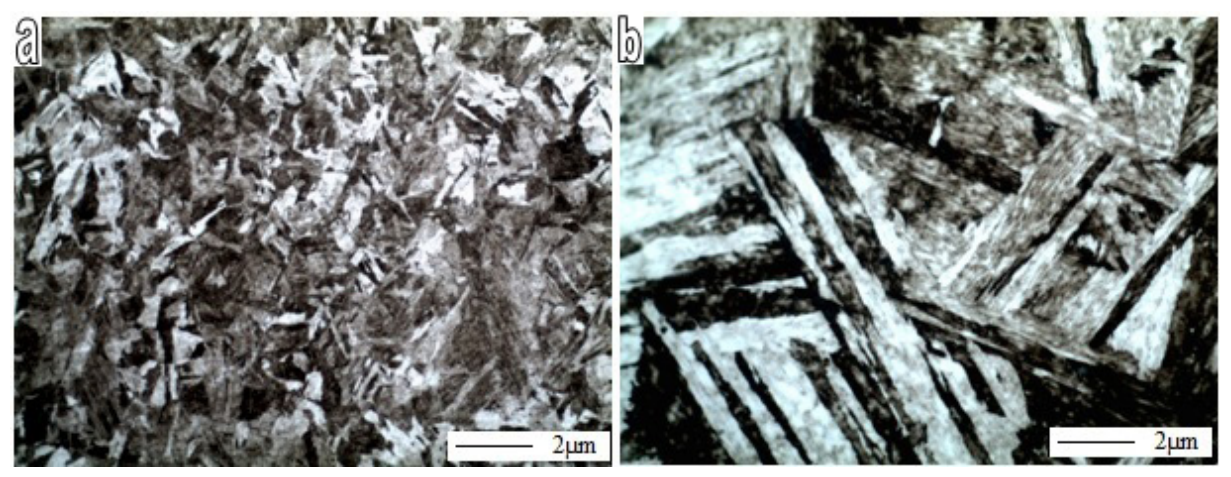

Figure 4. Martensite plates in refined austenitic grains solution annealed at $860^{\circ} \mathrm{C}$ (a). Blocks of martensite in coarser grains solution annealed at $1050^{\circ} \mathrm{C}(\mathrm{b})$.

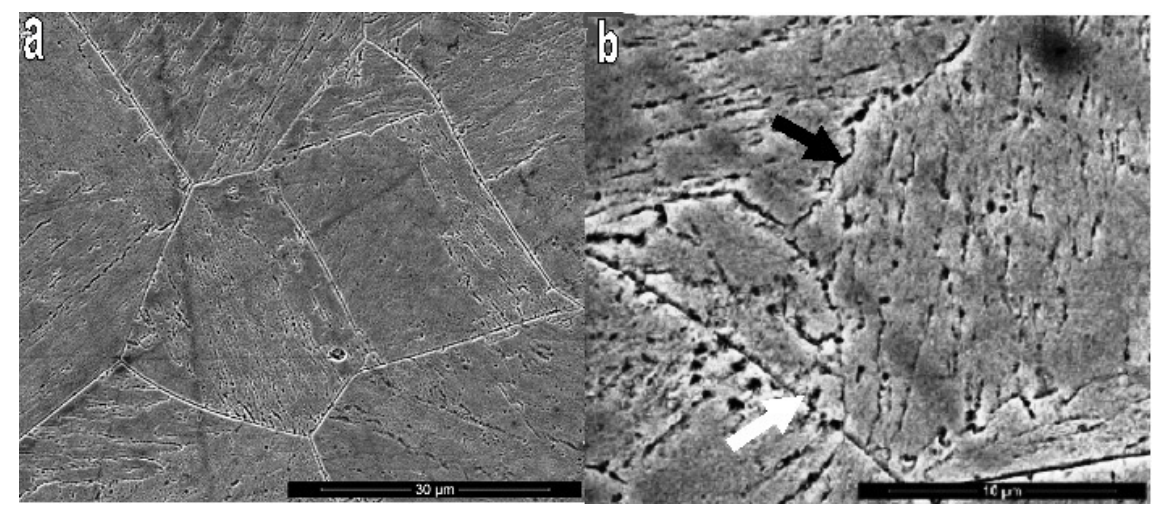

Figure 5. SEM images of the Maraging 300 solution annealed at $1000^{\circ} \mathrm{C}$. Austenite grain boundaries (a) delineating the blocks of martensite (b). The black arrow indicates a high angle boundary. The white arrow indicates an austenite grain boundary.

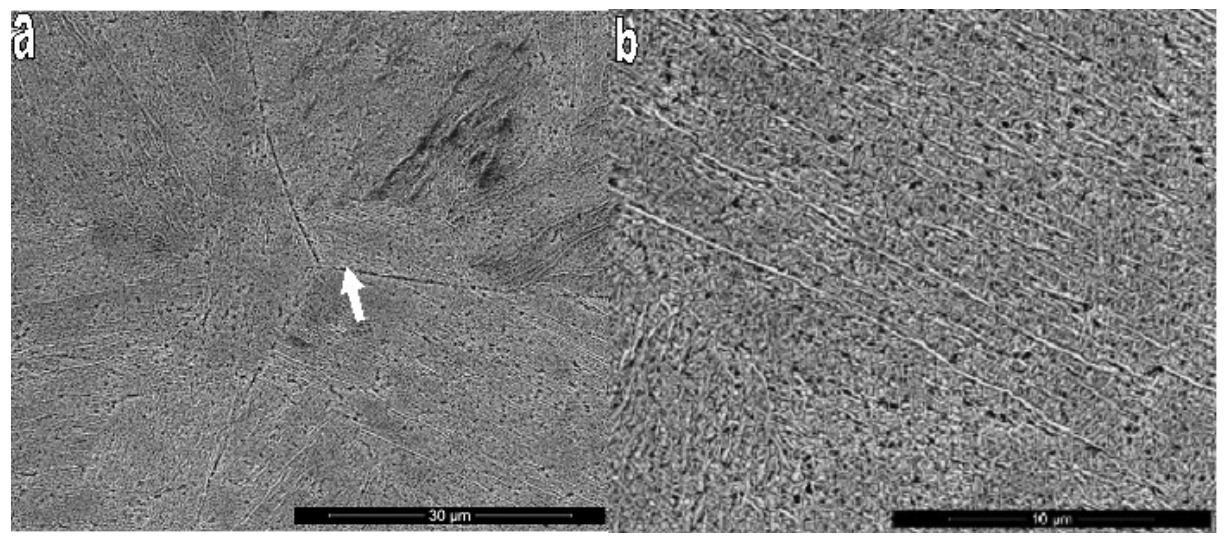

Figure 6. SEM images of the Maraging 300 solution annealed at $1100^{\circ} \mathrm{C}$. Austenite grain boundaries indicted by the arrow (a) and lath martensite (b).

The width of the martensite blocks was measured through images obtained by EBSD analysis (Figure 7). The blocks increase, while lath martensite decreases with the temperature of the solution annealing. This aspect of the martensite transformation agrees with the findings of several studies of other special alloys ${ }^{28-34}$. An increase of the martensite metastable phase nucleation rate during cooling promotes a decrease in the width of the lath, due to the increased volume of the grains and the greater chemical homogenization of the austenitic grain. This may be important for the mechanical performance of the alloy, especially with respect to its plane strain fracture toughness.
Table 2 gives the mechanical properties as a function of the temperature of the solution annealing. The hardness does not change significantly with an increase in the temperature, except for the samples solution annealed at $1100^{\circ} \mathrm{C}$, where the significant decrease of the hardness can be attributed to the remarkable growth of the austenite grain (Figure 8).

The energy absorbed during the impact tests reaches a statistically significant peak in samples solution annealed at $1000{ }^{\circ} \mathrm{C}$, delimiting the transition that occurs in the impact fracture micro-mechanisms (Figure 9). Even though the TiC volumetric fraction predicted by the phase simulation was too low to be detected by XRD analysis, the fractographic 
Table 2. Mechanical properties of the Maraging 300 steel.

\begin{tabular}{|c|c|c|c|c|c|c|c|c|}
\hline $\begin{array}{c}\text { Solution } \\
\text { temperature }\left({ }^{\circ} \mathrm{C}\right)\end{array}$ & $\begin{array}{c}\text { Tensile strength } \\
(\mathrm{MPa})\end{array}$ & $\begin{array}{c}\text { Yield strength } \\
\text { (MPa) }\end{array}$ & $\begin{array}{c}\text { Elongation } \\
(\%)\end{array}$ & Necking (\%) & $\begin{array}{l}\text { Strain hardening } \\
\text { coef. }\end{array}$ & $\begin{array}{l}\text { Charpy } \\
\left(\mathrm{J} / \mathrm{cm}^{2}\right)\end{array}$ & $K_{\mathrm{Ic}}$ & $\begin{array}{c}\text { Hardness } \\
\text { (HRC) }\end{array}$ \\
\hline 820 & $2067 \pm 31.6$ & $2052 \pm 28.8$ & $9.2 \pm 1.07$ & $13.1 \pm 2.92$ & $0.18 \pm 0.06$ & 15.5 & 60 & 54.8 \\
\hline 860 & $1994 \pm 75.3$ & $1981 \pm 73.75$ & $9.7 \pm 0.60$ & $16.2 \pm 1.20$ & $0.21 \pm 0.05$ & 17.67 & 65 & 55.7 \\
\hline 1000 & $1928 \pm 65.9$ & $1912 \pm 62.4$ & $10.4 \pm 0.92$ & $17.5 \pm 2.50$ & $0.18 \pm 0.03$ & 22.67 & 76 & 55.3 \\
\hline 1050 & $1831 \pm 81.8$ & $1808 \pm 42.6$ & $10.4 \pm 0.79$ & $17.8 \pm 1.27$ & $0.22 \pm 0.02$ & 11 & 78 & 55.5 \\
\hline 1100 & $1802 \pm 86.0$ & $1776 \pm 89.7$ & $9.0 \pm 0.44$ & $14.7 \pm 1.92$ & $0.21 \pm 0.02$ & 14 & 83 & 52.1 \\
\hline
\end{tabular}

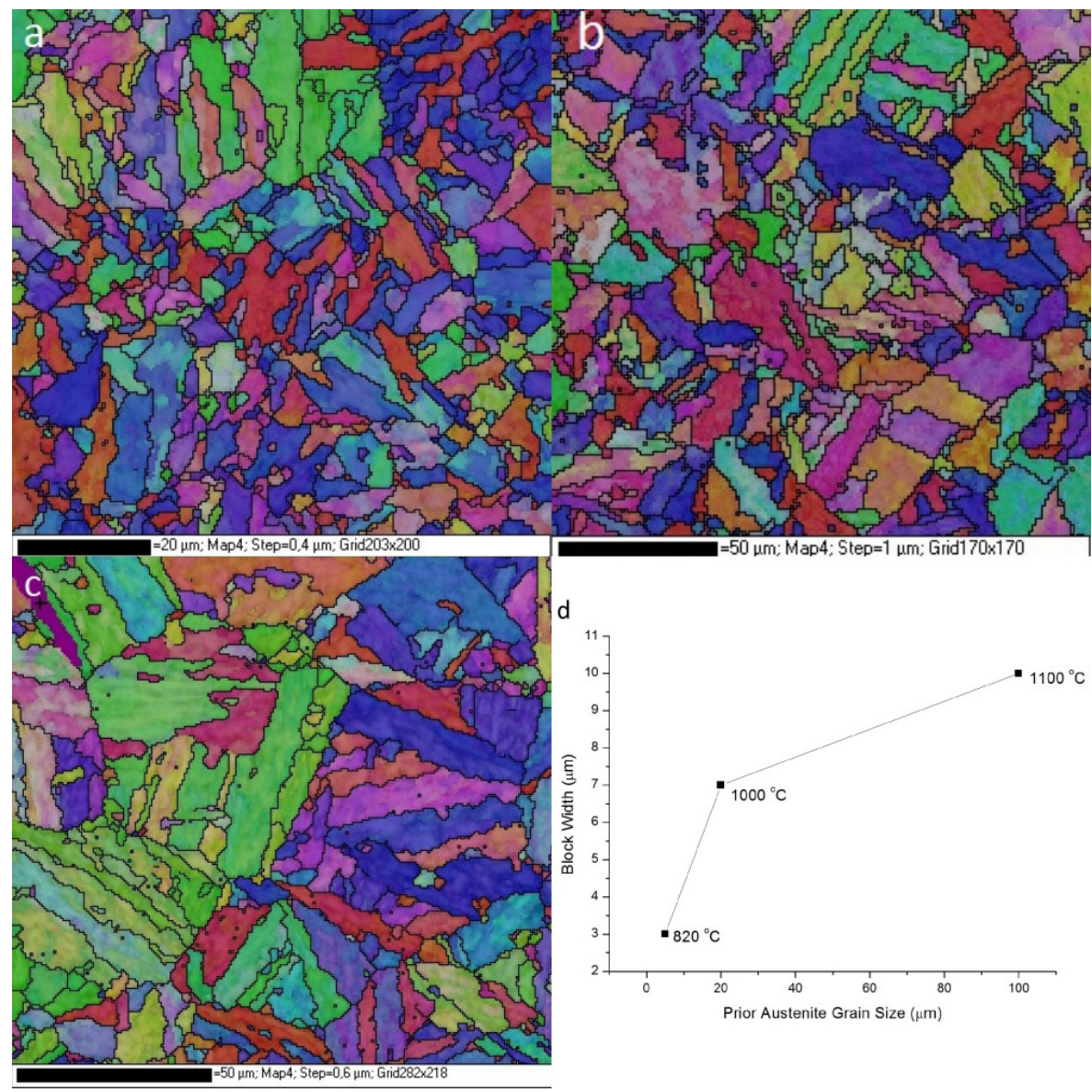

Figure 7. Blocks of martensite solution annealed at $820^{\circ} \mathrm{C}(\mathrm{a}) ; 1000^{\circ} \mathrm{C}(\mathrm{b}) ; 1100{ }^{\circ} \mathrm{C}(\mathrm{c})$; Relation between the prior austenite grain size and the martensite blocks (d).

analysis was able to identify the effect on the fracture behavior of the samples. The lower impact energy at lower temperatures is explained by the network of shallow dimples arising from fine undissolved particles, when this network delineates dimples and quasi-cleavage facets on the martensitic plates. The energy peak at $1000^{\circ} \mathrm{C}$ can be attributed to the dissolution of a large number of particles ${ }^{20}$, which begins the austenite grain growth and decreases the dimple nucleation sites. Therefore, the dimples become deeper and wider, which indicates an increase in strain energy until the final fracture. In this beginning of the austenite growth, the martensite is in the form of blocks and lath martensite is not yet evident. The perception of the cleavage facets mixed with dimples becomes easier by raising the temperature above $1000{ }^{\circ} \mathrm{C}$. Lath martensite preferably disposed with the preferential fracture systems favours the formation of a cleavage micro-

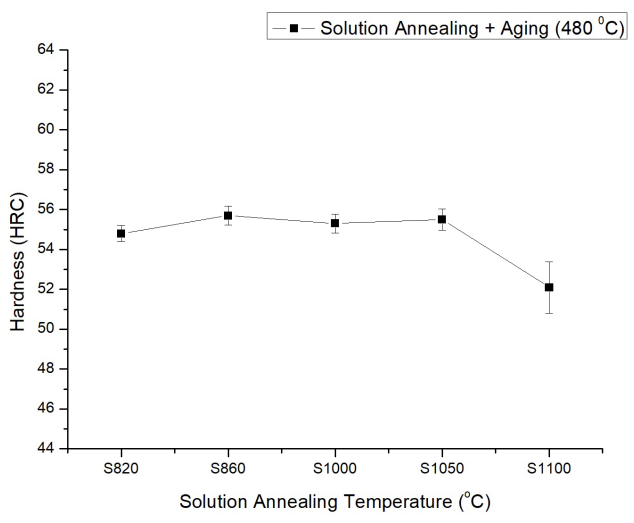

Figure 8. Hardness (HRC) as a function of the temperature of the solution annealing. 
mechanism at higher strain rates, which explains the energy decrease for higher temperatures.

Both tensile and yield strength decrease linearly with increasing solution annealing temperature and austenite grain size (Figure 10), which agrees with previous studies ${ }^{22,35}$. The ductility and strain hardening coefficient, on the other hand, remained statistically constant as a function of temperature ${ }^{36,37}$. Dimples were the only micro-mechanism found on the tensile fracture surfaces, and their size increases with the temperature of the solution annealing.

The fracture toughness KIC increases with temperature (Figure 11). The austenite grain growth enhances the

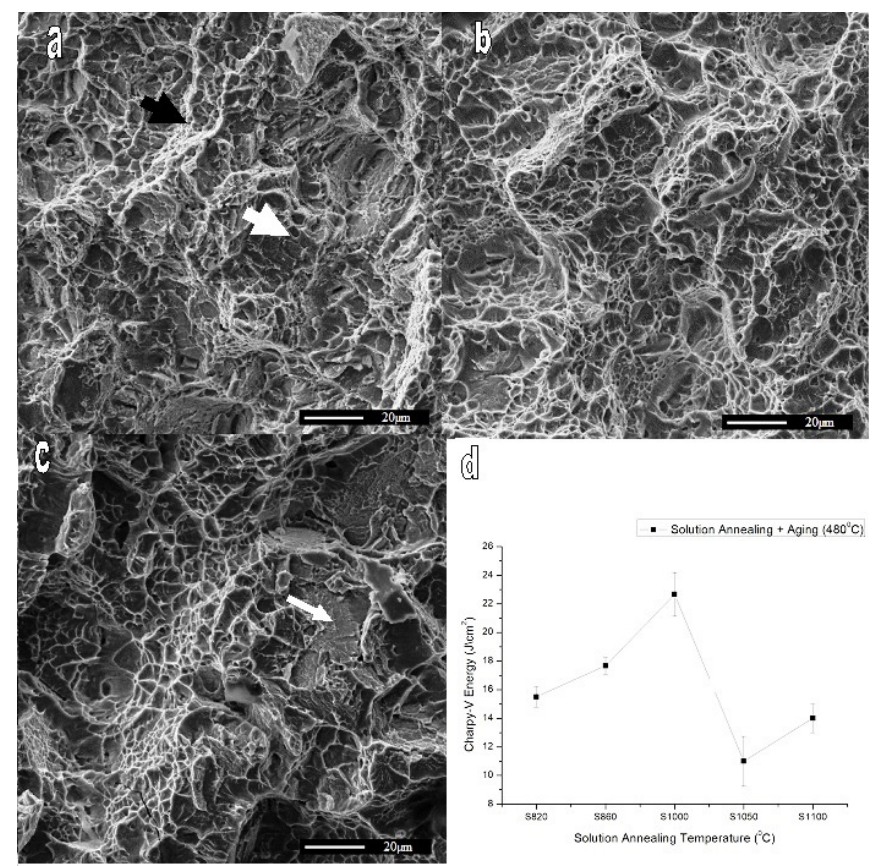

Figure 9. Network of shallow dimples (black arrow) delineating dimples and quasi-cleavage sites (white arrow) in solution at $860^{\circ} \mathrm{C}(\mathrm{a})$; homogeneously distributed dimples in solution at $1000^{\circ} \mathrm{C}(\mathrm{b})$; dimples mixed with cleavage facets (white arrow) in solution at $1050^{\circ} \mathrm{C}$ (c). Energy absorbed in the impact tests as a function of temperature of the solution annealing (d).

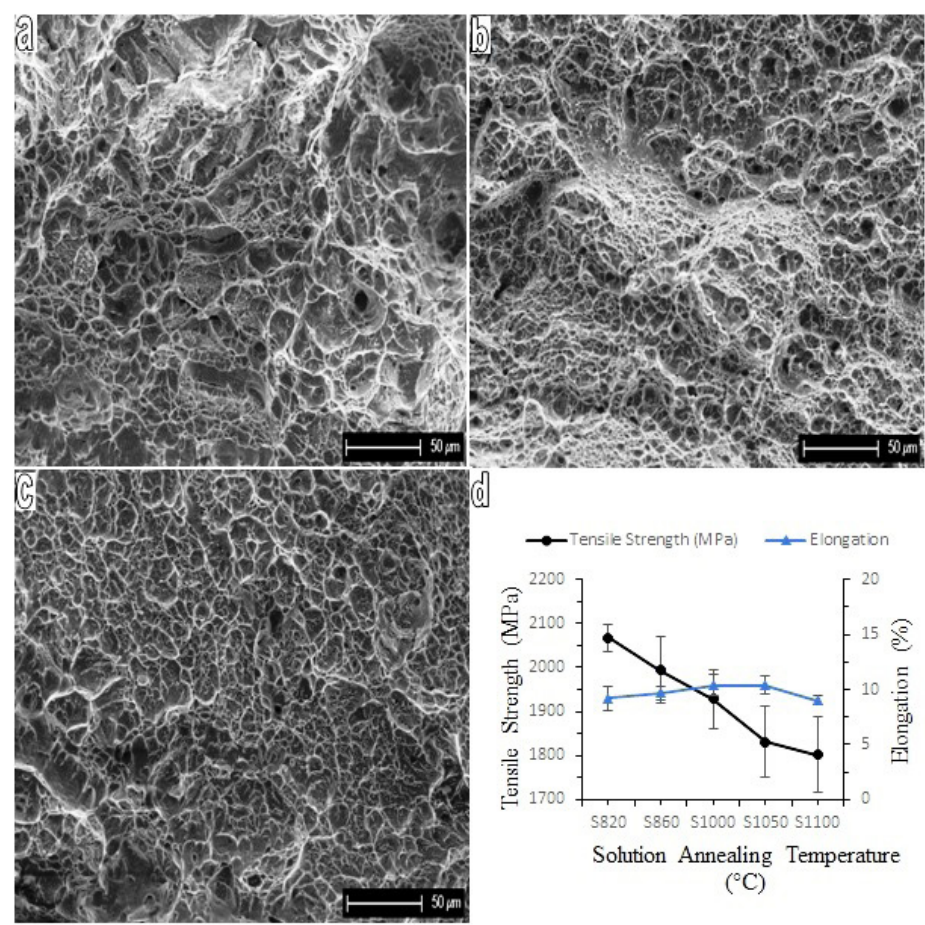

Figure 10. Fractographies of tensile samples showing dimples in solutions at: $860{ }^{\circ} \mathrm{C}(\mathrm{a}) ; 1000{ }^{\circ} \mathrm{C}(\mathrm{b}) ; 1050{ }^{\circ} \mathrm{C}(\mathrm{c})$; Tensile properties as a function of the temperature of the solution annealing (d). 


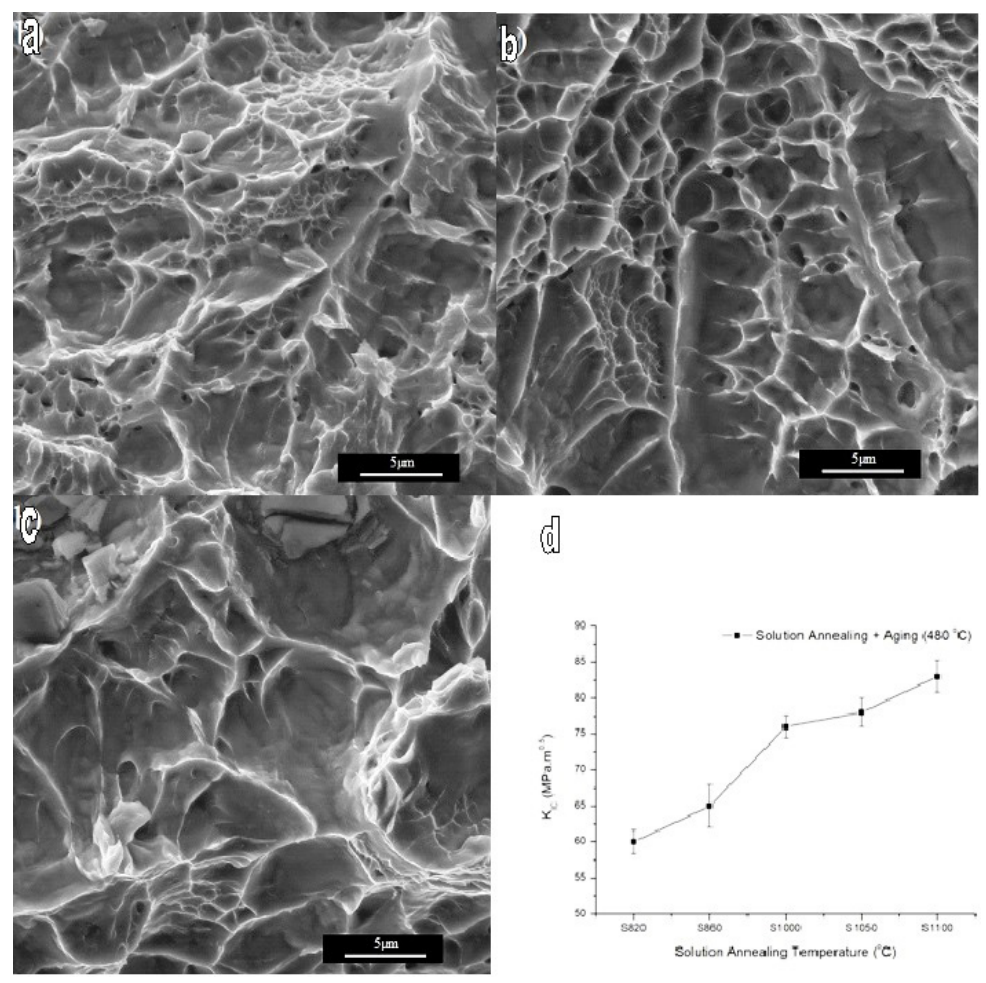

Figure11. Dimples of heterogeneous sizes in solution at $820^{\circ} \mathrm{C}$ (a); homogeneously distributed dimples in solution at $1000^{\circ} \mathrm{C}(\mathrm{b})$; larger dimples in solution at $1050^{\circ} \mathrm{C}$ (c). Fracture toughness as a function of the temperature of the solution annealing (d).

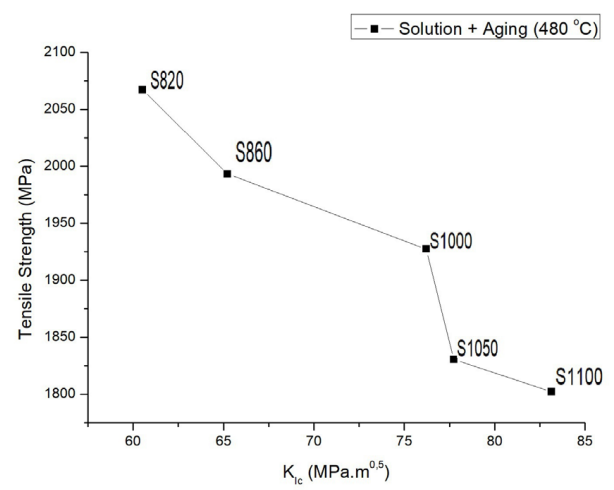

Figure 12. Relation between fracture toughness $\left(K_{\mathrm{Ic}}\right)$ and tensile strength of the Maraging steel solution annealed at $1000^{\circ} \mathrm{C}$ and aged at $480^{\circ} \mathrm{C}$.

formation of lath martensite, and consequently gives an advantage to the fracture toughness. The network of fine and shallow dimples occurring due to the undissolved particles at lower temperatures, between $820^{\circ} \mathrm{C}$ and $860^{\circ} \mathrm{C}$, such as seen in the impact test fractographies, is repeated here, but now it delineates larger dimples instead of quasi-cleavage. Homogeneously distributed dimples occurring for the samples solution annealed at $1000^{\circ} \mathrm{C}$ indicate that the particles have been dissolved. Increasing the temperature to 1050 and $1100{ }^{\circ} \mathrm{C}$ expands the dimples, providing higher toughness. Here, the difference for the Charpy test is that for samples solution annealed above $1000^{\circ} \mathrm{C}$ there was no cleavage, so the fracture toughness increased.
The low strain rate applied during the tensile and fracture toughness tests allows a sequence of displacements of the lath martensite to the preferential strain systems, which requires some increase of energy consumption ${ }^{32}$. The high strain rate of the impact tests, on the other hand, does not allow the displacement of the lath. This is the reason for the increase in fracture toughness while the impact energy decreases with the evolution of lath martensite ${ }^{32,33}$. The compromise between fracture toughness and tensile strength is optimal at a temperature of $1000^{\circ} \mathrm{C}$ (Figure 12). Solution annealing at $1000^{\circ} \mathrm{C}$ and aging at $480^{\circ} \mathrm{C}$ is the heat treatment that maximizes fracture toughness with the lowest loss of tensile strength for the studied Maraging 300 alloy, producing a 21\% increase in plane strain fracture toughness with a decrease of only $6.83 \%$ in the yield strength and $6.77 \%$ in the tensile strength, with respect to the commercial heat treatment.

\section{Conclusions}

The present study aimed to analyse the effect of the temperature of the solution annealing on the prior austenite grain size and the martensite morphology of Maraging 300 steel, and its consequences for the best compromise between fracture toughness and tensile strength. The findings allow the following conclusions:

- Primary austenite grain grows sharply after 1000 ${ }^{\circ} \mathrm{C}$, when the martensite morphology changes from equiaxial martensite plates in fine prior austenite grains to martensite blocks and lath martensite in coarsened austenite; 
- The microstructural transformation drives the impact energy, which reaches its peak at $1000{ }^{\circ} \mathrm{C}$, and drops from then on because of the cleavage mixed with dimple fracture micro-mechanisms. Cleavage is favoured in the fracture preferential systems of the lath martensite subjected to higher strain rates; The fracture toughness increases, and the tensile strength decreases with the temperature of the solution annealing as the lath martensite in austenitic coarse grains favours the formation of dimples at lower strain rates;

- Solution annealing at $1000{ }^{\circ} \mathrm{C}$ and aging at 480 ${ }^{\circ} \mathrm{C}$ is the heat treatment that maximizes fracture toughness with the lowest tensile strength loss for the studied Maraging 300 alloy, producing a 21\% increase in plane strain fracture toughness with a decrease of only $6.83 \%$ in the yield strength and $6.77 \%$ in the tensile strength, with respect to the commercial heat treatment.

\section{Acknowledgements}

The authors would like to thank CNPq and Capes for financial support.

\section{References}

1. Raabe D, Ponge D, Dmitrieva O, Sander B. Designing ultrahigh strength steels with good ductility by combining transformation induced plasticity and martensite aging. Adv Eng Mater. 2009;11(7):547-55.

2. Muneki S, Kawabe Y, Nakazawa K, Yaji H. Strengthening and toughening of maraging steel of over $280 \mathrm{kgf} / \mathrm{mm}^{2}$. Tetsu-toHagani. 1978;64(5):605-14. in Japanese.

3. Pawlack SJ, Zalecki W. Microestructure, properties and hot deformability of the new maraging steels. J Achiev Mater Manuf Eng. 2008;29:31-8.

4. Rao MN. Progress in understanding the metallurgy of $18 \%$ nickel maraging steels. Int J Mater Res. 2006;97(11):1594-607.

5. ASM International. ASM specialty handbook . Materials Park: ASM International; 2000. Nickel, Cobalt, and their alloys; p. 8.

6. Floreen S. The physical metallurgy of maraging steels. Metall Rev. 1968;13(1):115-28.

7. Nioata A. Researches regarding the optimization of thermal treatment depending on hardness for maraging 300 steel. Metabk. 2013;52(2):231-4.

8. Kłaput J. Influence of aging temperature on mechanical properties of the precipitation hardened martensitic mar vac 300 steel. Mechanika. 2015;112(3):61-9.

9. Leitner H, Schober M, Schnitzer R, Zinner S. Strengthening behaviour of Fe-Cr-Ni-Al-(Ti) maraging steel. Mater Sci Eng A. 2011;528(15):5264-70.

10. Turk C, Zunko H, Aumayr C, Leitner H, Kapp M. Advances in maraging steels for additive manufacturing. Berg Huettenmaenn Monatsh. 2019;164(3):112-6.

11. Arabi H, Divandari M, Hosseini HM. The effect of Ti contents on the amounts of inclusions formation and mechanical properties of C300 high strength steel. Iran J Mater Sci Eng. 2006;3:1-7.

12. Sinha PP, Sreekumar K, Natarajan A, Nagarajan KV. Grain growth in $18 \mathrm{Ni} 1800 \mathrm{MPa}$ maraging steel. J Mater Sci. 1991;26(15):4155-9.

13. Johnson WC, Stein DF. A study of grain boundary sergeants in thermally embrittled maraging steel. Metall Trans. 1974;5(3):54954.
14. Rack HJ, Kalish D. The strength and fracture toughness of 18 Ni (350) maraging steel. Metall Trans. 1971;2(2):3011-20.

15. Sinha PP, Sreekumar K, Babu NS, Pant B, Natarajan A, Nagarajan KV. Development of heat treatment parameters to improve fracture toughness and grain size of an embrittled maraging steel. J Heat Treat. 1992;9(2):125-31.

16. Tewari R, Mazumder S, Batra IS, Dey GK, Banerjee S. Precipitation in $18 \mathrm{wt} \% \mathrm{Ni}$ maraging steel of grade 350 . Acta Mater. 2000;48(5):1187-200.

17. Pardal JM, Tavares SSM, Cindra Fonseca MP, Abreu HFG, Silva JJM. Study of the austenite quantification by X-ray diffraction in the $18 \mathrm{Ni}-\mathrm{Co}-\mathrm{Mo}$-Ti maraging 300 steel. J Mater Sci. 2006;41(8):2301-7.

18. Liu K, Shan Y, Yang Z, Liang J, Lu L, Yang K. Effect of aging on microstructure and mechanical property of $1900 \mathrm{MPa}$ grade maraging stainless steel. J Mater Sci Technol. 2007;23:312-7.

19. Malakondaiah G, Srinivas M, Rao PR. Ultra high strength low alloy steels with enhanced fracture toughness. Prog Mater Sci. 1997;42(1-4):209-42.

20. Tavares SSM, Pardal JM, Martins TRB, Schmitt VM, Szlejf JFV. Influence of austenitizing on the mechanical properties of maraging 300 and SAE 4340 steels: comparative study. Mater Res. 2017;20(Suppl 2):2-8.

21. Lima VX Fo, Barros IF, Abreu HFG. Influence of solution annealing on microstructure and mechanical properties of maraging. Mater Res. 2016;20(1):20.

22. Rack HJ. Age hardening-grain size relationships in $18 \mathrm{Ni}$ maraging. Mater Sci Eng. 1978;34(3):263-70.

23. Patterson RL, Wayman GM. The crystallography and growth of partially-twinned martensite plates in Fe-Ni alloys. Acta Metall. 1966;14(3):347-69.

24. Hosford W.F. Mechanical behaviour of materials. 2nd ed. Cambridge: Cambridge University Press; 2012.

25. Andersson JO, Helander T, Höglund L, Shi P, Sundman B. Thermo-Calc \& Dictra, Computational tools for materials science. Calphad. 2002;26(2):273-312.

26. Maxwell PC, Goldberg A, Shyne JC. The influence of grain size and stress on the morphology of a 300 -grade maraging steel. Metall Trans. 1970;1:2759-66.

27. Tamura I, Tsuzaki K, Maki T. Morphology of lath martensite formed from deformed austenite in $18 \% \mathrm{Ni}$ maraging steel. $\mathrm{J}$ Phys Colloq. 1982;43(C4):551-6.

28. Long S, Liang Y, Jiang Y, Liang Y, Yang M, Yi Y. Effect of quenching temperature on martensite multi-level microestructures and properties of strength and toughness in 20CrNi2Mo steel. Mater Sci Eng A. 2016;676:38-47.

29. Iwashita K, Murata Y, Tsukada Y, Koyama T. Formation mechanism of the hierarchic structure in the lath martensite phase in steels. Philos Mag. 2011;91(35):4495-513.

30. Mirzaev DA, Okishev KY. Formation of packet (lath) martensite in iron - nickel alloys. Metal Sci Heat Treat. 2015;56(9-10):4629.

31. Morsdorf L, Jeannin O, Barbier D, Mitsuhara M, Raabe D, Tasan CC. Multiple mechanisms of lath martensite plasticity. Acta Mater. 2016;121:202-14.

32. Liang Y, Long S, Xu P, Lu Y, Jiang Y, Liang Y, et al. The important role of martensite laths to fracture toughness for the ductile fracture controlled by the strain in EA4T axle steel. Mater Sci Eng A. 2017;695:154-64.

33. Changsheng X, Zhengdong L, Xikou H, Xitao W, Shibin Q. Effect of martensite-austenite constituents on impact toughness of pre-tempered MnNiMo bainitic steel. Mater Charact. 2020;161:110139.

34. Morito S, Yoshida H, Maki T, Huang X. Effect of block size on the strength of lath martensite in low carbon steels. Mater Sci Eng A. 2006;438-440:237-40. 
35. Saul G, Roberson JA, Adair AM. The effects of thermal treatment on the austenitic grain size and mechanical properties of $18 \%$ Ni maraging steels. Metall Trans. 1970;1(2):383-7.

36. Ashfari H, Shamanian M, Emadi R, Saeidi N. Correlation of tensile properties and strain hardening behaviour with martensite volume fraction in dual-phase steels. Kolkata: The Indian Institute of Metals; 2016. p. 1-10.

37. Zhen F, Zhang K, Guo Z-L, Qu J-B. Effect of martensite fine structure on mechanical properties of an $1100 \mathrm{MPa}$ grade ultrahigh-strength steel. J Iron Steel Res Int. 2015;22(7):645-51. 